\title{
RESEARCH
}

\section{PREVALENCE AND TREATMENT APPROACHES OF IMPACTED TEETH IN OLDER ADULTS}

Turkish Journal of Geriatrics

DOI: 10.31086/tigeri.2020.191

2020; 23(4): 524-533

- Hasan Onur ŞiMŞEK ${ }^{1}$ D

- Gökhan ÖZKAN² (D)

- Umut DEMETOĞLU1
CORRESPONDANCE

${ }^{1}$ Hasan Onur Şimşek

Aydin Adnan Menderes University, Faculty of Dentistry, Oral and Maxillofacial Surgery, Aydin, Turkey

Phone: +90256 2133939

e-mail: hasanonursimsek@gmail.com

Received: Aug 04, 2020

Accepted: Nov 10, 2020

${ }^{1}$ Aydin Adnan Menderes University, Faculty of Dentistry, Oral and Maxillofacial Surgery, Aydin, Turkey

${ }^{2}$ Aydın Adnan Menderes University, Faculty of Dentistry, Oral and Maxillofacial Radiology, Aydın, Turkey

\section{Abstract}

Introduction: The primary aim of our study was to identify the problems caused by impacted teeth and to discuss treatment alternatives in older adults. The secondary aim of the study was to investigate the presence, frequency, and position of impacted teeth in older adults and to investigate the reasons for impaction.

Materials and Methods: The study included 79,733 patients who were admitted to the Aydın Adnan Menderes University, Faculty of Dentistry since December 2013. From these patients, 8,670 panoramic radiographs of patients aged 60 years and older were evaluated retrospectively.

Results: The most common impacted teeth were the third molar $(453,77.3 \%)$, canine $(109,18.6 \%)$, and premolar $(13,2.2 \%)$. There was a statistically significant difference between the presence of an impacted tooth and the outcome of treatment $(p<0.001)$. Of the $(216,51.8 \%)$ patients for whom surgical tooth extraction was prescribed, $(159,38.1 \%)$ underwent extraction, while $(57,13.7 \%)$ patients refused treatment.

Conclusions: Routine follow-up should be recommended for asymptomatic teeth that do not cause significant problems in the adjacent teeth and surrounding tissues instead of prophylactic extraction in all age groups, especially in older adults.

Keywords: Tooth, Impacted; older adults; Radiography, Panoramic 


\section{INTRODUCTION}

Advanced age is a physiological condition that causes social and health problems worldwide. Nowadays, significant changes are observed in population distribution charts. The overall progress of medical methods and living conditions has led to an increase in the average life span, especially in developed countries. According to the World Health Organization (WHO) and the United Nations (UN), the age group of 60 and over is considered older adults. By 2050 , it is estimated that over $12 \%$ of people in the world will fit into this age group $(1,2)$. In certain areas of our territory, there are places where the older adults lives more longer in Turkey. This means older adults need more specific attention. It is necessary to plan required treatments while considering the physical and mental limitations of older adults, as well as their quality of life and needs (3). For older adults who are still active, special dental treatments may be needed to provide function, phonation, and aesthetics. A number of surgical procedures may be required to regain the function of mastication in the elderly. In this study, reliable diagnosis, treatment concepts, and possible outcomes will be discussed for impacted teeth with different clinical characteristics. The sample size of the patient group differs from other studies in terms of searching for a diagnosis and treatment approaches. In the present study, the frequency of impacted teeth can be determined in older adults, and, at the same time, the clinician will learn treatment alternatives that can be administered in the presence of impacted teeth in older adults.

\section{MATERIALS AND METHODS}

The study included 79,733 patients who were admitted to the Aydın Adnan Menderes University, Faculty of Dentistry since December 2013. Among these patients, 8,670 panoramic radiographs of patients aged 60 years and older were evaluated retrospectively. The study was designed retrospectively in accordance with the principles of the Helsinki Declaration. The approval for the study was obtained from the Clinical Research Ethics Committee of Aydın Adnan Menderes University, Faculty of Dentistry (approval no.: ADÜDHF 2017-014).

Panoramic radiographs and demographic information such as age, gender, and systemic diseases of patients were obtained from patient records. The count and number of impacted teeth on the first panoramic radiographs of the patients were recorded. The position and depth of the impacted teeth, the presence of adjacent teeth, and the problems and pathological conditions of the impacted teeth and adjacent teeth, if any, were determined.

The depth of the impacted teeth according to the alveolar bone level was recorded as mucosa, partially impacted, or complete bone retention based on the enamel-cement boundary. The depth of impacted teeth to the occlusal plane was recorded according to the classification of Quek et al.: Class A, not impacted in bone, or the occlusal plane of the impacted tooth is at the same level as the adjacent tooth; Class B, partially impacted in bone, or the occlusal plane of the impacted tooth is between the occlusal plane and the cervical line of the adjacent tooth (if any part of the cementoenamel junction was lower than the bone level); or Class C, completely impacted in bone, or the occlusal plane of the impacted tooth is apical to the cervical line of the adjacent tooth (4). The angulations of impacted teeth were determined according to two lines drawn along the longitudinal axes of the impacted teeth and the sagittal plane. These were classified as vertical, mesioangular, horizontal, distoangular, buccolingual, and ectopic (other), based on Winter's classification $(5,6)$.

The patients' examination records and treatment procedures along with the demographic and descriptive data were analyzed. The treatment planned and administered for impacted teeth were noted from the patient records. The data were analyzed using the statistical software package SPSS 20.0 (Armonk, NY, IBM Corp.). Descriptive statistics were given as numbers and percentages. To determine the correlation between categorical variables, 
Pearson's chi-squared test was performed. A p-value of $<0.05$ was considered statistically significant.

\section{RESULTS}

The mean age of the 8,670 patients aged 60 years and older included in the study was 66.23 years (std. error $=0.312)$. In the study, 179 (3.99\%) of the 4,480 female patients and 238 (5.68\%) of the 4,190 male patients had at least one impacted tooth. A total of 586 impacted teeth were detected, including at least one impacted tooth in 417 of the 8,670 patients participating in the study.

According to the International Classification of Diseases (ICD-11) endorsed by the WHO, of the 417 patients, 268 (64.2\%) had circulatory system diseases and 126 (30.2\%) had endocrine and metabolic disorders.

The most common impacted teeth were the third molars $(453,77.3 \%)$, canines $(109,18.6 \%)$, premolars $(13,2.2 \%)$, and other teeth $(11,1.9 \%)$. In the distribution of teeth by gender, there were 173 impacted maxillary teeth in the females and 144 impacted maxillary teeth in the males, while there were 73 impacted mandibular teeth in the females and 196 impacted mandibular teeth in the males.
The distribution of teeth according to their numbers is shown in detail in Table I.

The effect of gender on impacted teeth was analyzed in terms of the presence of problems. Of the 179 female patients with impacted teeth, $42.5 \%$ had problems, while $57.5 \%$ didnot have problems. Of the 238 male patients with impacted teeth, $48.7 \%$ had problems, while $51.3 \%$ did not have problems. There was no statistically significant relationship between the presence of problems in impacted teeth, the depth of the impacted teeth, the angulation of the impacted teeth, treatment, and gender. Of the patients with impacted mandibular teeth, $71.8 \%$ were male and $28.2 \%$ were female, while of the patients with impacted maxillary teeth, $47.6 \%$ were male and $52.4 \%$ were female. There was a statistically significant difference between the type of impacted teeth (whether mandibular or maxillary) and gender $(p<0.001)$ (Table II).

In the study, 288 patients had one impacted tooth, while 129 patients had more than one impacted tooth. The highest number of impacted teeth was five in one patient. There was no statistically significant relationship between the count of impacted teeth and gender $(p=0.598)$. When the impaction depth and angulations of the teeth were

Table 1. Distribution of impacted tooth numbers by gender

\begin{tabular}{|c|c|c|c|c|c|c|c|}
\hline \multirow{2}{*}{$\begin{array}{c}\text { Maxillary teeth } \\
\text { number }\end{array}$} & \multicolumn{3}{|c|}{ Distribution } & \multirow{2}{*}{$\begin{array}{c}\text { Mandibular } \\
\text { teeth number }\end{array}$} & \multicolumn{4}{c|}{ Distribution } \\
\cline { 2 - 4 } & Female & Male & Total & & Female & Male & Total \\
\hline 13 & 29 & 17 & $46(7.8 \%)$ & 33 & 5 & 4 & $9(1.5 \%)$ \\
\hline 15 & 2 & 0 & $2(0.3 \%)$ & 35 & 1 & 0 & $1(0.2 \%)$ \\
\hline 18 & 46 & 47 & $93(15.9 \%)$ & 38 & 37 & 92 & $129(22 \%)$ \\
\hline 21 & 1 & 0 & $1(0.2 \%)$ & 43 & 3 & 3 & $6(1 \%)$ \\
\hline 23 & 33 & 15 & $48(8.2 \%)$ & 44 & 0 & 2 & $2(0.3 \%)$ \\
\hline 25 & 1 & 2 & $3(0.5 \%)$ & 45 & 4 & 1 & $5(0.9 \%)$ \\
\hline 28 & 57 & 61 & $118(20.1 \%)$ & 48 & 22 & 91 & $113(19.3 \%)$ \\
\hline sup & 4 & 42 & $6(\% 1)$ & sup & 1 & 3 & $4(0.7 \%)$ \\
\hline
\end{tabular}


Table 2. Data distribution table of impacted teeth by gender

\begin{tabular}{|c|c|c|c|c|}
\hline \multirow{2}{*}{\multicolumn{2}{|c|}{$\begin{array}{l}\text { Female } \\
\text { n (\%) }\end{array}$}} & \multicolumn{3}{|c|}{ Gender } \\
\hline & & \multirow{2}{*}{$\begin{array}{c}\text { Male } \\
\text { n (\%) } \\
76(42.5)\end{array}$} & $p$ value & \\
\hline \multirow{2}{*}{ Impacted Tooth Problem - Pathology } & Yes & & $116(48.7)$ & \multirow{2}{*}{0.203} \\
\hline & No & $103(57.5)$ & $122(51.3)$ & \\
\hline \multirow{3}{*}{ Treatment } & Extraction & $45(25.1)$ & $78(32.8)$ & \multirow{3}{*}{0.104} \\
\hline & Follow-up & $114(63.7)$ & $144(60.5)$ & \\
\hline & Refusal of Treatment & $20(11.2)$ & $16(6.7)$ & \\
\hline \multirow{2}{*}{$\begin{array}{l}\text { Impacted Tooth Mandible-Maxilla } \\
\text { Classification }\end{array}$} & Mandible & $46(28.2)$ & $117(71.8)$ & \multirow{2}{*}{$<0.001$} \\
\hline & Maxilla & $133(52.4)$ & $121(47.6)$ & \\
\hline \multirow{3}{*}{ Depth of Impacted Tooth } & A & $11(6.1)$ & $22(9.2)$ & \multirow{3}{*}{0.226} \\
\hline & B & $40(22.3)$ & $64(26.9)$ & \\
\hline & C & $128(71.5)$ & $152(63.9)$ & \\
\hline \multirow{6}{*}{ Angulation of Impacted Tooth } & Vertical & $54(30.2)$ & 64 (26.9) & \multirow{6}{*}{0.869} \\
\hline & Mesioangular & $67(37.4)$ & $82(34.5)$ & \\
\hline & Distoangular & $23(12.8)$ & $36(15.1)$ & \\
\hline & Horizontal & $24(13.4)$ & $38(16)$ & \\
\hline & Ectopic & $8(4.5)$ & $14(5.9)$ & \\
\hline & Buccolingual & $3(1.7)$ & $4(1.7)$ & \\
\hline
\end{tabular}

analyzed, it was found that 165 (28.2\%) teeth were vertical, 196 (33.4\%) teeth were mesioangular, 80 (13.7\%) teeth were distoangular, 100 (17.1\%) teeth were horizontal, 31 (5.3\%) teeth were ectopic, and 14 (2.4\%) teeth were buccolingual. In terms of the depth of the impacted tooth, $46(7.8 \%)$ teeth had mucosal retention without bone retention, 149 (25.4\%) teeth had partial bone retention, and 391 (66.7\%) teeth had bone retention (TablellI).

When the clinical and radiological findings of the impacted teeth were analyzed, no complications were observed in 323 (55.1\%) teeth, while various problems were observed in 263 (44.9\%) teeth. In terms of the complications of impacted teeth, it was found that 72 teeth were carious, 38 teeth were exposed into the mouth due to the use of a prosthesis, 67 teeth had pericoronitis, 52 teeth had an enlarged follicle, 16 teeth had cystic formations, and 18 teeth were malposed and microdontic. Of the teeth adjacent to the impacted teeth, 51 were carious and had root resorption and periodontal problems due to impacted teeth. The most common indications for impacted tooth extraction were pericoronitis in 53 (33.3\%) teeth, caries in 38 (23.9) teeth, and prosthetic exposure in $28(17.6 \%)$ teeth. Table 4 shows the distribution of problems and treatments of the impacted and adjacent teeth (TablelV).

When all the treatments administered to the patients due to impacted teeth were analyzed, it was found that the patients had indications for extraction or follow-up with a clinician. Of the 216 (51.8\%) patients for whom surgical tooth extraction was prescribed, 159 (38.1\%) underwent extraction, while 57 (13.7\%) patients refused treatment. The decision not to extract was made for 370 patients, and those teeth were followed up on. 
Table 3. Descriptive data of impacted teeth

\begin{tabular}{|c|c|c|c|}
\hline & Description & Frequency & Percent \% \\
\hline \multirow[t]{6}{*}{ Number of Impacted Teeth } & 1 & 288 & 69.1 \\
\hline & 2 & 100 & 24.0 \\
\hline & 3 & 19 & 4.6 \\
\hline & 4 & 9 & 2.2 \\
\hline & 5 & 1 & 0.2 \\
\hline & Total & 417 & 100.0 \\
\hline \multirow[t]{7}{*}{ Impacted Teeth Position-Angulation } & Vertical Position & 165 & 28.2 \\
\hline & Mesioangular Position & 196 & 33.4 \\
\hline & Distoangular Position & 80 & 13.7 \\
\hline & Horizontal Position & 100 & 17.1 \\
\hline & Ectopic Position & 31 & 5.3 \\
\hline & Buccolingual Position & 14 & 2.4 \\
\hline & Total & 586 & 100.0 \\
\hline \multirow[t]{4}{*}{ Impacted Teeth Position-Bone } & A: Not bony impacted & 46 & 7.8 \\
\hline & B: Partially impacted & 149 & 25.4 \\
\hline & C: Bony impacted & 391 & 66.7 \\
\hline & Total & 586 & 100.0 \\
\hline
\end{tabular}

There was a statistically significant relationship between the presence of impacted tooth problems and the treatment outcome $(p<0.001)$. Of the patients with impacted tooth problems, $59.7 \%$ underwent extraction, $22.4 \%$ were followed up on, and $17.9 \%$ refused treatment. Clinician follow-up was performed for the 311 (96.3\%) impacted teeth without a problem. Problems were observed in $89.1 \%$ of the cases with an impacted tooth at the depth of the mucosa level, $71.3 \%$ of the cases with partial bone retention, and only $29.7 \%$ of the impacted teeth at the depth of bone level, and there was a statistically significant relationship $(p<0.001)$. In terms of the mandibular-maxillary distribution of the impacted teeth and the presence of a problem, problems were detected in $59.4 \%$ of the impacted maxillary teeth and $48.9 \%$ of the impacted mandibular teeth, and there was a statistically significant relationship $(p=0.005)$ (TableV).

\section{DISCUSSION}

When the current population data are analyzed, it shows that our geriatric population is rapidly increasing. It is extremely important to regain the functions of oral and surrounding tissues in order to increase the quality of life and awareness levels of older adults, as well as their participation in their social environments. Missing teeth are the most common clinical condition in the geriatric group (7). Because of the resultant increase in quality of life and sociocultural developments, dental rehabilitation needs to become more significant in this age group of patients. The examinations performed on our older adults showed that some patients were 
Table 4. Presence of problem in impacted and adjacent teeth

\begin{tabular}{|c|c|c|c|c|c|c|}
\hline \multicolumn{2}{|c|}{ Extraction } & \multicolumn{3}{|c|}{ Treatment } & \multirow[t]{2}{*}{ Total } & \multirow[b]{2}{*}{$p$ value } \\
\hline & & $\begin{array}{l}\text { Clinician } \\
\text { Follow-up }\end{array}$ & $\begin{array}{l}\text { Refusal } \\
\text { of Treat- } \\
\text { ment }\end{array}$ & & & \\
\hline \multirow{7}{*}{$\begin{array}{l}\text { Presence of impacted } \\
\text { tooth problem }\end{array}$} & Caries & $38(23.9 \%)$ & $14(3.7 \%)$ & $20(35 \%)$ & 72(\%12.3) & \multirow{8}{*}{$<0.001$} \\
\hline & Prosthetic exposure & $28(17.6 \%)$ & $8(2.1 \%)$ & $2(3.5 \%)$ & $38(\% 6.5)$ & \\
\hline & Pericoronitis & $53(33.3 \%)$ & $2(0.5 \%)$ & $12(21 \%)$ & $67(\% 11.4)$ & \\
\hline & Enlarged follicle & $11(6.9 \%)$ & $30((8.1 \%)$ & $11(19.2 \%)$ & $52(\% 8.9)$ & \\
\hline & Dentigerous cyst & $14(8.8 \%)$ & $0(0 \%)$ & $2(3.5 \%)$ & $16(\% 2.7)$ & \\
\hline & Microdontia-Malposed & $13(8.1 \%)$ & $5(1.3 \%)$ & $\mathrm{O}(0 \%)$ & $18(\% 3)$ & \\
\hline & None & $2(1.2 \%)$ & $311(84 \%)$ & $10(17.5 \%)$ & $323(\% 55.1)$ & \\
\hline \multicolumn{2}{|l|}{ Total } & 159 & 370 & 57 & 586 & \\
\hline \multirow{4}{*}{$\begin{array}{l}\text { Presence of adjacent } \\
\text { tooth problem }\end{array}$} & Caries & $6(3.7 \%)$ & $3(0.8 \%)$ & $3(5.2 \%)$ & $12(2.0 \%)$ & \multirow{5}{*}{0.029} \\
\hline & Root resorption & $5(3.1 \%)$ & $9(2.4 \%)$ & $3(5.2 \%)$ & $17(2.9 \%)$ & \\
\hline & Periodontal problem & $10(6.2 \%)$ & $10(2.7 \%)$ & $2(3.5 \%)$ & $22(3.8 \%)$ & \\
\hline & None & 138(86.7\%) & $348(94 \%)$ & 49(85.9\%) & $535(91.3 \%)$ & \\
\hline \multicolumn{2}{|l|}{ Total } & 159 & 370 & 57 & 586 & \\
\hline
\end{tabular}

aware of their impacted teeth and that others were unaware of them.

The primary aim of our study was to identify the problems caused by impacted teeth and to discuss treatment alternatives in older adults. The secondary aim of the study was to investigate the presence, frequency, and position of impacted teeth in older adults and to investigate the reasons for impaction. In the literature, most studies on impacted teeth include all age groups, not older adults alone $(6,8)$. The present study evaluated the impacted tooth status of only older adults. There are few studies specifically on impacted teeth in older adults $(2,9$, 10). In their study on edentulous patients, Miloglu et al. (11) reported that 16 (5.6\%) of 283 patients had impacted teeth. This study also examined other dental problems along with impacted teeth. Hastar et al. (10) reported that 6 of 106 (\%5.7) patients over 60 years of age had impacted teeth. Canines and third molars are the most commonly encountered impacted teeth. Trybek et al. (2) found the preva- lence of impacted teethto be $1.2 \%$ in older adults. The inclusion of only patients undergoing surgical procedures in the study may have contributed tothe low prevalence. The number of patients $(8,670)$ included in our study is quite high compared to other studies. The prevalence of impacted teeth in older adults in our study (4.8\%) was consistent with the general literature.

Another parameter that we examined in our study is the position of impacted teeth in the bone, since in most cases, eruption problems may occur in teeth that are not in their normal position (12). Pathological conditions may also occur in impacted teeth, leading to tooth position abnormalities. Despite the presence of various classifications, there is no tooth position classification that includes all teeth. Most studies on impacted teeth include impacted third molars, which are the most commonly encountered impacted teeth (13). In our study, we determined the positions of the teeth in the bone using the Pell and Gregory classification to deter- 
mine tooth depth and Winter's classification to determine angular positioning. These are the most commonly used classifications in the literature for impacted teeth. Hashemipour et al. evaluated the position of impacted third molars based on the classification of Pell and Gregory and Winter. In their study, the authors reported that the most common angulation of impaction in the mandible was mesioangular impaction (48.3\%), the most common angulation of impaction in the maxilla was vertical impaction (45.3\%), and impaction in level IIA was the most common in both the maxilla and the mandible (14). Quek et al. (4) suggested that the mesioangular impaction of the mandibular third molar was the most common type of impaction (60\%). In our study, all impacted teeth were examined, and the majority of the impacted teeth were the third molars, with the most common impaction in the mesioangular position. Examination of the eruption depth revealed that the most common type of impacted tooth was an impacted tooth with bone retention.

It can be predicted that bone retention that is too deep reduces the risk of complications in older adults. The extraction requirement for teeth with partial bone or mucosal retention may be high due to the potential of complications. This is thought to be related to the longer duration of prosthe- sis use by these patients and the exposure of impacted teeth in the mouth as a result of increased bone destruction and changes in the oral mucosa with ageing. Most of the symptomatic pathological problems caused by the third molars occur as a result of a partially erupted tooth. The problems associated with a complete bony impaction have a lower incidence.

Impacted teeth may cause pathologies both in themselves and in the adjacent teeth and surrounding tissues. Examples of such pathologies include root resorption of adjacent teeth, periodontal disease, pericoronitis, dental caries, odontogenic cysts and tumors, teeth under dental prostheses, jaw fracture, unexplained pain, and intracoronary resorption $(2,4,8,15-18)$. In a study, Gisakis et al. (8) reported that the following pathologies associated with impacted teeth occurred in all age groups: (a) caries of the impacted and/or adjacent teeth (93 cases, 9.9 $\%) ;(b)$ periodontal bone loss of the adjacent tooth more than $5 \mathrm{~mm}$ below the cementoenamel junction (242 cases, 25.7\%); (c) root resorption of the adjacent tooth (183 cases, 19.5\%); (d) an increase in the pericoronal space of the dental follicle more than 4 $\mathrm{mm}$ around the impacted tooth (116 cases, 12.3\%); and (e) orthodontic complications. In our study, caries, prosthetic exposure, pericoronitis, enlarged

Table 5. Distribution of impacted tooth problems

\begin{tabular}{|c|c|c|c|c|}
\hline \multirow{2}{*}{\multicolumn{2}{|c|}{$\begin{array}{c}\text { Yes } \\
n(\%)\end{array}$}} & \multicolumn{3}{|c|}{ Impacted Tooth Problem - Pathology } \\
\hline & & $\begin{array}{c}\text { No } \\
n(\%)\end{array}$ & $p$ value & \\
\hline \multirow{3}{*}{ Treatment - Outcome } & Extraction & $157(59.7)$ & $2(0.6)$ & \multirow{3}{*}{$<0.001$} \\
\hline & Follow-up & $59(22.4)$ & $311(96.3)$ & \\
\hline & Refusal of Treatment & 47 (17.9) & $10(3.1)$ & \\
\hline \multirow{3}{*}{ Depth of Impacted Tooth } & A & $41(89.1)$ & $5(10.9)$ & \multirow{3}{*}{$<0.001$} \\
\hline & B & $106(71.1)$ & $43(29.9)$ & \\
\hline & C & $116(29.7)$ & $275(70.3)$ & \\
\hline \multirow{2}{*}{$\begin{array}{l}\text { Impacted Tooth Mandible-Maxilla } \\
\text { Classification }\end{array}$} & Mandible & $137(52.1)$ & $131(40.6)$ & \multirow{2}{*}{0.005} \\
\hline & Maxilla & $126(47.9)$ & $192(59.4)$ & \\
\hline
\end{tabular}


dental follicles, cysts, malposition, and tooth shape anomalies were observed in the impacted tooth, while the pathological conditions associated with the tooth adjacent to the impacted tooth included caries, root resorption, and periodontal problems. These pathological conditions were found to be consistent with the general literature.

However, not every problem seen in impacted teeth is an indication for extraction. Older adults tend to be more medically complex and have higher risks associated with invasive treatments. Older adults requesting certain procedures can often invoke ethical dilemmas in which patient autonomy seemingly challenges nonmalfeasance or "do not harm" (19). A compilation of treatment options for impacted teeth is presented to assist dentists in discussing the sequelae of impacted teeth as well as the complications of treatment with their patients. A differential diagnosis for an impacted tooth is not possible without clinical assessment. The treatment options for the management of impacted teeth are categorized into four options: observation, intervention, relocation, and extraction (20). A surgical extraction is recommended when local factors are favorable. Trybek et al. stated that the indications for surgical extractions included prosthetic reasons (72\%), pain symptoms related to pericoronal infection or a difficult tooth eruption process $(22 \%)$, or caries (6\%) (2).

In the present study, $10 \%$ of patients refused treatment or did not come to their appointment. Ikebe et al. (21) recommended different treatment options to their patients with missing teeth. According to this study, older adults generally preferred safer and simpler procedures. The risk of possible complications should be considered in surgical extraction in patients above 60 years $(2,22)$. Most of the complications associated with surgical extraction are postoperative problems: for example, alveolar osteitis, postoperative infection, and hematoma (2). With increasing age, various changes can be seen in the bone and, accordingly, in the alveolar bone. Volumetric reductions occur in the cortical and trabecular bones. As a result, the bone may become more brittle. A study by Chuang et al. investigating age as a risk factor showed a higher incidence of complications (18.3\%). The most common complications were alveolar osteitis (7.4\%), inferior alveolar nerve injury (1.6\%), unexpected trismus (1.2\%), and postoperative infection (1.1\%) (23). The weakening of the mandible as a result of a reduction in bone elasticity during ageing may be the cause of the greater incidence of intraoperative fractures reported among patients in the fifth decade (24). For high-risk extractions (in older adults, with deep bony impaction, or with the presence of associated pathology), it may be necessary to offer specific diet instruction for at least four weeks postoperatively (24). The general contraindications for the extraction of impacted teeth can be grouped into three primary categories: advanced patient age, poor health, and surgical damage to adjacent structures (13). Some limitations of the study include a lack of knowledge about whether and how many of the patients' impacted teeth were extracted in the preadmission period and the carrying out of radiological examinations through panoramic radiographs.

\section{CONCLUSION}

While planning treatment approaches for impacted teeth in older adults who have multiple diseases and cannot manage their care, clinical problems should be considered. When impacted teeth remain in the mouth for a long time, it may cause various problems. However they can also stay in the jaws without any problems for many years. Routine follow-up should be recommended for asymptomatic teeth that do not cause significant problems in the adjacent teeth and surrounding tissues instead of prophylactic extraction in all age groups, especially older adults. 


\section{REFERENCES}

1. United Nations, Deparment of Economic and Social Affairs, Population Division. World population prospects: The 2015 revision, Key Findings and Advance Tables. United Nations New York; 2015. [Internet]. Available from: https://population.un.org/wpp/ Publications/Files/Key_Findings_WPP_2015.pdf. Accessed: 23.03.2020.

2. Trybek G, Chruściel-Nogalska M, Machnio $M$ et al. Surgical extraction of impacted teeth in elderly patients. A retrospective analysis of perioperative complications-the experience of a single institution. Gerodontology 2016; 33: 410-415 (PMID: 25643646).

3. Hashemipour MA. Dental management and oral complications in elderly. Turkish Journal of Geriatrics 2009; 12(4): 198-201.

4. Quek S, Tay C, Tay K, Toh S, Lim K. Pattern of third molar impaction in a singapore chinese population: A retrospective radiographic survey. International Journal of Oral and Maxillofacial Surgery 2003; 32: 548-552 (PMID: 14759117).

5. Hou R, Kong L, Ao J et al. Investigation of impacted permanent teeth except the third molar in chinese patients through an x-ray study. Journal of Oral and Maxillofacial Surgery 2010; 68: $762-767$ (PMID: 20307762).

6. Msagati F, Simon EN, Owibingire S. Pattern of occurrence and treatment of impacted teeth at the $\mathrm{Mu}$ himbili National Hospital, Dar es Salaam, Tanzania. BMC Oral Health 2013; 13: 37 (PMID: 23914842).

7. Uzun $\mathrm{H}$, Nazlıel Çelenligil $\mathrm{H}$. Medical, dental history and extraoral, intraoral and dental findings in the elderly. Turkish Journal of Geriatrics 2000; 3: 15-21(in Turkish).

8. Gisakis IG, Palamidakis FD, Farmakis ETR, Kamberos G, Kamberos S. Prevalence of impacted teeth in a Greek population. Journal of Investigative and Clinical Dentistry 2011; 2: 102-109 (PMID: 25426603).

9. Doğan BG, Gökalp S. Tooth loss and edentulism in the Turkish elderly. Archives of Gerontology and Geriatrics 2012; 54: e162-e66 (PMID: 22293677).

10. Haştar E, Yılmaz H, Orhan H. Findings from panoramic radiographs on the edentulous elderly patients. SDU The Journal of Health Science 2010; 1: 82-87 (in Turkish).

11. Miloglu Ö, Yasa Y, Bayrakdar I, Gungor H. Panoramic radiographic examination in a group of edentulous patients. J Dent Fac Atatürk Uni 2012; 22: 230-234 (in Turkish).
12. Şimşek HO, Kömerik N, Koca CG. Differences and similarities of third molar impaction in the mandible and in the maxilla. Journal of International Oral Health 2017; 9: 258-264 (DOI: 10.4103/jioh. jioh_150_17).

13. LJ Peterson. Principles of management of impacted teeth. In: Peterson LJ EEI, Hupp JR, Tucker MR (Eds). Contemporary Oral and Maxillofacial Surgery. 4th edition, CV Mosby, St. Louis, USA 2003, pp 184-213.

14. Hashemipour MA, Tahmasbi-Arashlow M, Fahimi-Hanzaei F. Incidence of impacted mandibular and maxillary third molars: A radiographic study in a southeast Iran population. Med Oral Patol Oral Cir Bucal 2013; 18: e140 (PMID: 23229243).

15. Şimşek-Kaya G, Melih-Ömezli M, Yapici G, Dayi E, Ertaş U. Prevalence of impacted premolars in a Turkish population and considerations for surgical treatment. Med Oral Patol Oral Cir Bucal 2011; 16: e781-6 (PMID: 21196868).

16. Özden B, Acikgoz A. Prevalence and characteristics of intracoronal resorption in unerupted teeth in the permanent dentition: A retrospective study. Oral Radiology 2009; 25: 6 (DOI: 10.1007/s11282-009-00033).

17. Patil S, Halgatti V, Khandelwal S, Santosh B, Maheshwari S. Prevalence of cysts and tumors around the retained and unerupted third molars in the Indian population. Journal of Oral Biology and Craniofacial Research 2014; 4: 82-87 (PMID: 25737923).

18. Yıldırım D, Şimşek HO, Karaturgut UE, Kapucuoğlu FN. Hypoesthesia due to a dentigerous cyst: A case report. Balıkesir Health Science Journal 2013; 2(2): 125-127 (in Turkish)

19. Wang TT, Wolff MS, Panchal N. The graying of America: Considerations and training needs for geriatric patient care. Journal of Oral and Maxillofacial Surgery 2019; 77: 1741-1742 (PMID: 31002788).

20. Frank CA. Treatment options for impacted teeth. The Journal of the American Dental Association 2000; 131: 623-632 (PMID: 10832256).

21. Ikebe K, Hazeyama T, Ogawa T et al. Subjective values of different age groups in japan regarding treatment for missing molars. Gerodontology 2011; 28: 192-196 (PMID: 20545773).

22. Baensch F, Kriwalsky MS, Kleffmann W, Kunkel M. Third molar complications in the elderly-a matched-pairs analysis. Journal of Oral and Maxillofacial Surgery 2017; 75: 680-686 (PMID: 28011325). 
23. Chuang S-K, Perrott DH, Susarla SM, Dodson TB. Age as a risk factor for third molar surgery complications. Journal of Oral and Maxillofacial Surgery 2007; 65: 1685-1692 (PMID: 17719384).
24. Bodner L, Brennan PA, McLeod NM. Characteristics of iatrogenic mandibular fractures associated with tooth removal: Review and. analysis of 189 cases. British Journal of Oral and Maxillofacial Surgery 2011; 49: 567-572 (PMID: 20947226). 